\title{
Olfactory Neuroepithelium Cells from Cannabis Users Display Alterations to the Cytoskeleton and to Markers of Adhesion, Proliferation and Apoptosis
}

\author{
Alejandra Delgado ${ }^{1}$, Maria Hidalgo ${ }^{1}$, Marta Barrera ${ }^{2}$, Carmen Duran ${ }^{1}$, Carmen Castro $^{3}$, \\ Cristina Fernandez ${ }^{4}$, Rafael de la Torre ${ }^{5}$, Ismael Sanchez ${ }^{1}$, Victor Perez ${ }^{6}$, Noelia \\ Geribladi-Doldán ${ }^{3}$, Patricia Robledo ${ }^{2}$, and Esther Berrocoso ${ }^{1}$ \\ ${ }^{1}$ University of Cadiz \\ ${ }^{2}$ IMIM-Hospital del Mar Research Institute \\ ${ }^{3}$ Universidad de Cadiz \\ ${ }^{4}$ Pompeu Fabra University \\ ${ }^{5}$ Hospital del Mar Institute for Medical Research \\ ${ }^{6}$ Centro de Investigación Biomédica en Red de Salud Mental (CIBERSAM), Instituto de \\ Salud Carlos III
}

August 25, 2020

\begin{abstract}
Background and Purpose: Cannabis is the third most commonly used psychoactive substance of abuse, yet it also receives considerable attention as a potential therapeutic drug. Therefore, it is essential to fully understand the actions of cannabis in the human brain. The olfactory neuroepithelium $(\mathrm{ON})$ represents an interesting surrogate model to study the effects of drugs in the brain, since it is closely related to the central nervous system, and sensory olfactory neurons are continually regenerated from populations of stem/progenitor cells that undergo neurogenesis throughout life. Experimental Approach: In this study, we used ON cells from chronic cannabis users and healthy control subjects to assess alterations in relevant cellular processes, and to identify changes in functional proteomic pathways due to cannabis consumption. Key Results: The ON cells from cannabis users exhibited alterations in the expression of proteins that were related to the cytoskeleton, cell proliferation and cell death, as well as, changes in proteins implicated in cancer, gastrointestinal and neurodevelopmental pathologies. Subsequent studies showed cannabis provoked an increase in cell size and morphological alterations evident through $\beta$-Tubulin III staining, as well as, enhanced beta-actin expression and a decrease in the ability of ON cells to undergo cell attachment, suggesting abnormalities of the cytoskeleton and cell adhesion system. Furthermore, these cells proliferated more and underwent less cell death. Conclusion and Implications: Our results indicate that cannabis may alter key processes of the developing brain, some of which are similar to those reported in mental disorders like DiGeorge syndrome, schizophrenia and bipolar disorder.
\end{abstract}

\section{INTRODUCTION}

Cannabis is the most widely used illicit substance worldwide, and both the use and misuse of this substance is increasing in many countries. In Europe, the lifetime prevalence of cannabis use is about five times higher than that of other illicit substances. Many concerns have been raised regarding the adverse effects of cannabis use during adolescence, with suggestions that it may lead to the development of substance use disorders or mental disorders, such as psychosis, depression, bipolar disorder or anxiety (Campeny et al., 2020). However, there is data arguing that cannabis is a safe and natural alternative for the treatment of a variety of medical and mental health conditions (Maccarrone et al., 2017). Thus, one of the outstanding challenges is to define 
the neuropathological mechanisms specifically altered by cannabis that may trigger psychiatric conditions in vulnerable populations. Unfortunately, despite the enormous amount of information coming from animal models, genetic and human neuroimaging data (Szutorisz and Hurd, 2016; Bloomfield et al., 2019), there is still an important lack of information from human neuronal tissue and live cells that addresses the effects of cannabis in the nervous system.

In adulthood, the differentiation of precursor cells into neurons continues in several brain structures and in some peripheral tissue, such as the olfactory neuroepithelium (ON). In the ON, olfactory sensory neurons are continually regenerated throughout life from stem or progenitor cells by neurogenesis, these populations located at the apical and basal membranes (Leung et al., 2007). Thus, the ON contains multipotent cells that can proliferate in vitro and that can differentiate into multiple cell types, including neurons and glia (Matigian et al., 2010). As they can be easily collected through nasal brushing, several studies have demonstrated the utility of the $\mathrm{ON}$ as a surrogate tissue to investigate disease related events that affect neurons in the brain. For example, cells isolated from the ON have been used to study the molecular profiles associated with such disease states, showing alterations in cell signalling pathways involved in cell proliferation, neurogenesis and cell adhesion in schizophrenia (Feron et al., 1999; McCurdy et al., 2006). In bipolar disorder, the cell death of ON cells is enhanced, and these cells display alterations of the cytoskeleton and in cell migration (McCurdy et al., 2006; Solis-Chagoyan et al., 2013; Munoz-Estrada et al., 2015). In the field of cannabis, we previously showed that ON cells obtained from cannabis users exhibit changes in the cannabinoid CB1 receptor, and in serotonin 2A receptor heteromer expression and function, both of which were associated with cognitive performance (Galindo et al., 2018). Furthermore, the macromolecular profile of ON cells is also altered in cannabis users, these cells displaying a modified lipid composition, as well as an increase in DNA and histone methylation (Saladrigas-Manjon et al., 2020).

We now explore the effect of prolonged cannabis use on protein expression in ON cells in the belief that this may provide novel insights into the cellular processes that are deregulated by cannabis consumption, events that may be related with neuropsychiatric disorders. We examined alterations in relevant cellular processes, and adopted a label-free proteomic approach to identify potential changes in functional pathways in ON cells as result of prolonged cannabis consumption.

\section{MATERIALS AND METHODS}

\subsection{Subjects}

Six cannabis users and 7 control subjects were recruited at the IMIM-Hospital del Mar Research Institute (Barcelona, Spain). The study was reviewed and approved by the local institutional ethics committee (CEIC-PSMAR). All subjects provided their written informed consent after the study and procedures were explained to them in full. All the subjects, of either sex, were between 18 and 40 years old, and the cannabis users consumed 5 or more cannabis cigarettes per week. Subjects were instructed to abstain from cannabis use for at least $12 \mathrm{~h}$ before testing. The subjects were excluded if they fulfilled any of the following criteria: (1) comply with the criteria for any severe mental disorder according to DSM-V; (2) any history of severe congenital, medical or neurological illness; (3) a history of severe mental illness among first degree relatives; (4) consumption of other drugs of abuse except alcohol and tobacco; and (5) present any medical condition with nasal repercussions (rhinitis or bleeding). The consumption of cannabis was verified by testing for tetrahidrocannabinol (THC) metabolites in urine (Instant-View, Multipanel 10 Test Drug Screen: Alfa Scientific Designs, USA). The exclusion criteria were verified using the Hamilton Depression Rating Scale (HDRS-17), the individual's clinical history and a diagnostic interview according to DSM-V criteria (SCID). Furthermore, a Neurological Evaluation Scale was used to evaluate neurological soft signs (NSS (Buchanan et al., 1989) and the Global Assessment of Functioning scale (GAF) was used to measure the level of functionality (Endicott et al., 1976).

\subsection{Neuropsychological evaluation}

Neuropsychological tests were performed to assess cognitive functioning. To evaluate attention, the spatial span direct recall with the Cambridge Neuropsychological Test Automated Battery (CANTAB (Cambridge 
Cognition, 2017) and the digit span direct recall (WAIS-III (Wechsler, 1997) tests were used. These analyses were performed with the measures of span length. Spatial span inverse recall (CANTAB) and the digit span inverse recall (WAIS-III) tests were used to assess working memory. The emotion recognition task (ERT, CANTAB) was used to determine social and emotional cognition, the semantic verbal fluency test (SVFT (Benton, 1983) was used for executive functions, and the vocabulary test (WAIS-III) was used to estimate premorbid intelligence.

\subsection{Measurement of cannabis consumption in plasma}

To estimate cannabis consumption, THC and its metabolites, 11-hydroxy-THC (11-OHTHC) and 11-nor-9carboxy- $\Delta$-9-THC (THC-COOH) were quantified in plasma, as reported previously (Galindo et al., 2018). We followed the Waters Corporation protocol with some modifications (Zhang et al., 2016). Briefly, $1 \mathrm{ml}$ of plasma was spiked with an internal standard d3- $\Delta$-9-THC $(10 \mu \mathrm{l} \mathrm{of} 1 \mu \mathrm{g} / \mathrm{ml}$ solution in $\mathrm{MeOH})$, and the protein was precipitated with $2 \mathrm{ml}$ of $0.1 \%$ formic acid in acetonitrile and centrifuged for 10 minutes at 3,500 $\mathrm{rpm}$. The supernatant was diluted in $4 \mathrm{ml}$ of MilliQ water and loaded to an Oasis Prime HLB $3 \mathrm{~cm}^{3}, 60$ mg column (Waters Co., USA). To wash the column, $2 \mathrm{ml}$ of $25 \%$ methanol was added and it was eluted by adding $2 \mathrm{ml}$ of 90:10 acetonitrile:methanol twice. A nitrogen stream was used at $<39{ }^{\circ} \mathrm{C}$ and $<15$ psi pressure to dry the organic phase. Analytes were reconstituted in $50 \mu \mathrm{l}$ of 90:10 ACN:MeOH and $50 \mu \mathrm{l}$ of MilliQ water, and THC and its metabolites were quantified in an Agilent 1200 series HPLC system coupled to a 6410 Triple Quadrupole LC-MS (Agilent Technologies, USA) mass spectrometer with an electrospray interface. Nitrogen was employed as a drying and nebulizing gas.

\subsection{Nasal brushing and cell culture}

Cells were exfoliated from the nasal cavity as described previously (Galindo et al., 2018), using specific brushes to obtain samples from the lower and middle turbinate through a circular movement. Cells were grown at $37{ }^{\circ} \mathrm{C}$ and with $5 \% \mathrm{CO}_{2}$ in Dulbecco's Modified Eagle Medium/Ham F-12 (DMEM/F12) (GibcoBRL, USA) containing 10\% FBS (GibcoBRL, USA), 2\% GlutaMAX 100X (Biowest, USA) and 1\% antibioticantimycotic (Thermo Scientific, USA). When confluent, the cells were detached with $0.25 \%$ trypsin-EDTA (GibcoBRL, USA), and about 200,000 cells were re-plated in $75 \mathrm{~cm}^{2}$ flasks and cultured in supplemented medium. All experiments were carried out on cells cultured to passage 6 .

\subsection{Sample preparation for proteomic analysis}

ON cells were cultured under proliferative conditions for five days and then lysed ( $1 \times 10^{6}$ cells per condition) in lysis buffer for protein extraction: 1\% NP40, $50 \mathrm{mM}$ HEPES [pH 7], $150 \mathrm{mM} \mathrm{NaCl}, 1 \mathrm{mM}$ EDTA, supplemented with protease inhibitors. Proteins (100 $\mu \mathrm{g} / \mathrm{sample})$ were precipitated in acetone overnight at $-20{ }^{\circ} \mathrm{C}$ and recovered by centrifugation at $17,000 \mathrm{~g}$ for 20 minutes at $4{ }^{\circ} \mathrm{C}$. Protein pellets were resuspended in $8 \mathrm{M}$ Urea in Tris $10 \mathrm{mM}[\mathrm{pH} 8]$, reduced with $10 \mathrm{mM}$ dithiothreitol at $50{ }^{\circ} \mathrm{C}$ for $30 \mathrm{~min}$ and alkylated with $50 \mathrm{mM}$ iodoacetamide for $20 \mathrm{~min}$ at room temperature (RT) in the dark. Samples were digested for 4h at RT with Lys-C enzyme/substrate (Promega (V167), USA) (enzyme/substrate ratio 1:50), and then diluted four times with $50 \mathrm{mM}$ ammonium bicarbonate for further trypsin digestion (Promega, USA) at $37{ }^{\circ} \mathrm{C}$ overnight (enzyme/substrate ratio 1:50). The digested peptides were desalted using a SepPak C18 cartridge and dried in a SpeedVac, prior to analysis by mass spectrometry (MS) using a label-free quantitative approach. Thus, peptide samples (approximately $500 \mathrm{ng} / \mathrm{sample}$ ) were loaded onto a nano-ACQUITY UPLC System (Waters, USA) connected on-line to an LTQ Orbitrap XL mass spectrometer (Thermo Electron, USA). An aliquot of each sample was loaded onto a Symmetry 300 C18 UPLC Trap column (180 $\mu \mathrm{m} x$ $20 \mathrm{~mm}, 5 \mu \mathrm{m}$ : Waters), and the pre-column was connected to a BEH130 C18 column (75 um x $200 \mathrm{~mm}$, $1.7 \mu \mathrm{m}$ : Waters, USA) and equilibrated in $3 \%$ acetonitrile and $0.1 \%$ formic acid. Peptides were eluted directly into an LTQ Orbitrap XL mass spectrometer (Thermo Finnigan, USA) through a nanoelectrospray capillary source (Proxeon Biosystems, Denmark) at $300 \mathrm{nl} / \mathrm{min}$ and using a 120 min linear gradient of 3-50\% acetonitrile. The mass spectrometer automatically switched between MS and MS/MS acquisition in datadependent acquisition mode. Full MS scan survey spectra (m/z 400-2000) were acquired in the orbitrap with mass resolution of 30,000 at $\mathrm{m} / \mathrm{z} 400$. After each survey scan, the six most intense ions above 1,000 counts 
were sequentially subjected to collision-induced dissociation (CID) in the linear ion trap. Precursors with charge states of 2 and 3 were selected specifically for CID and peptides were excluded from further analysis over $60 \mathrm{~s}$ using the dynamic exclusion feature.

A Progenesis LC-MS (Waters, USA) apparatus was used for the label-free analysis of differential protein expression. One run was used as a reference, to which the precursor masses in all the other samples were aligned. Only features comprising charges of $2+$ and $3+$ were selected, and the raw abundances of each feature were normalized automatically and converted to logarithms against the reference run. A peak list containing the information of all the features was generated and exported to the Mascot search engine (Matrix Science Ltd., UK). Differentially expressed proteins were defined as follows: p-value (t-test) $<0.05$ and fold-change rates $>1.5$ for up-regulated or $<0.6$ for down-regulated proteins identified in at least two

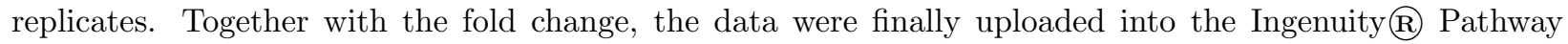
Analysis (IPA) software (Ingenuity Systems, USA) to investigate their molecular and biological functions.

\subsection{Immunocytochemistry}

Cells were plated on $13 \mathrm{~mm}$ round glass coverslips and incubated at $37{ }^{\circ} \mathrm{C}$ in $5 \% \mathrm{CO}_{2}$ prior to fixation for immunofluorescence, performing all experiments in triplicate: $1 \times 10^{4}$ cells/coverslip plated when cultures were maintained for 24 hours; $2 \times 10^{3}$ cells/coverslip when they were maintained for 5 days; and $2 \times$ $10^{4}$ cells/coverslip were plated when they were maintained for 7 days. The cells were fixed with $4 \%$ paraformaldehyde (PFA: Sigma-Aldrich Chemicals, Spain) in PBS for 20 minutes and after washing in PBS, the cells were incubated for 1 hour at RT in blocking solution: 10\% Bovine Serum Albumin (BSA: Sigma, Spain); $0.25 \%$ Triton-X 100; and 1\% FBS in PBS. The cells were then incubated overnight at $4{ }^{\circ} \mathrm{C}$ with the primary antibodies. Neuronal microtubules were stained with mouse anti- $\beta$-III-Tubulin (1:1,000 dilution: ThermoFisher (MA1-118), USA) and anti-GAP43 (1:1,000 dilution: Abcam (ab16053), UK), mesenchymal stem cell progenitors were stained with CD105 (1:100 dilution: Sigma-Aldrich Chemicals (HPA011862), Spain), while neural progenitors were stained with anti-Nestin (1:200 dilution: ThermoFisher (PA5-32517), USA), anti-GFAP (1:3,000 dilution: DAKO (Z0334), USA) and anti-NeuN (1:500 dilution: ThermoFisher (702022), USA), a specific marker for neurons. When anti-Ki67 was used, the cells were permeabilized with $0.2 \%$ Triton-X 100 in PBS for 25 minutes and then incubated for 20 minutes in blocking solution containing $4 \%$ FBS. The cells were incubated overnight at $4{ }^{\circ} \mathrm{C}$ with anti-Ki67 (1:100 dilution: ThermoFisher, USA) in a buffer containing $0.03 \%$ Triton-X 100 and 3\% BSA in PBS. The cells were incubated with the secondary antibodies for $1 \mathrm{~h}$ at RT: AlexaFluor488 donkey anti-Rabbit (1:1000 dilution: Invitrogen (A21206), USA) and AlexaFluor568 donkey anti-Mouse (1:1000 dilution: Invitrogen (A10037), USA). The nuclei were stained with 4', 6'-diamidino-2-phenylindole dihydrochloride (DAPI, 1:5,000 dilution: Panreac Applichem (A4099), Spain) and all the coverslips were then mounted with Fluoro-Gel medium (Electron Microscopy Sciences, USA). Images were acquired on an MMI CellCut plus (Olympus, Japan).

\subsection{Cell size and shape measurement}

Neuronal microtubules were identified by $\beta$-III-Tubulin immunostaining, as described above and in triplicate cultures for each sample. A total of 100 cells were assessed per subject from 15 random microscopy fields. The area and perimeter occupied by microtubules was defined and measured with the ImageJ software (USA). The formula used to assess roundness was: $\left(\right.$ perimeter $\left.^{2}\right) /\left(4^{*}\right.$ pi*area). A roundness value of 1.0 indicates a perfect circle, and higher values indicate oblong and non-circular objects (DeCoster et al., 2010).

\subsection{Focal adhesion immunolabelling}

To analyse focal adhesion, $2 \times 10^{3}$ cells were plated were plated on a coverslip as indicated in the datasheet for the "actin cytoskeleton and focal adhesion staining kit" (Merck (FAK100), Spain). Cells were permeabilized with $0.5 \%$ Triton-X 100 in PBS for 30 minutes and then incubated in blocking solution for 1 hour at RT, containing 1\% BSA. The primary anti-vinculin antibody (1:500 dilution: Merck (90227), Spain) was applied overnight $\left(4^{\circ} \mathrm{C}\right)$ and after washing $(5$ minutes) in three times, the cells were incubated for $1 \mathrm{~h}$ at RT with TRITC-conjugated Phalloidin (1:1000, Merck (90228), Spain) and an AlexaFluor488 Donkey anti-Mouse secondary antibody (1:1,000 dilution; ThermoFisher (A21202), USA). Images were acquired with an MMI 
CellCut plus (Olympus, Japan).

To quantify focal adhesions immunolabelled with anti-vinculin, images were analysed with ImageJ software (USA) and the total number of vinculin adhesion points were quantified per cell. The cell cultures were performed in triplicate and a total of 10 cells per sample were analysed.

\subsection{Western blot}

The extraction of total protein was performed by lysing the cells in Lysis buffer: 1\% NP40, 50 mM HEPES [pH 7], $150 \mathrm{mM} \mathrm{NaCl}, 1 \mathrm{mM}$ EDTA, supplemented with protease inhibitors. The protein samples (20 $\mu \mathrm{g}$ per well) were resolved by electrophoresis in TGX Stain Free Precast gels (Bio-Rad, Spain), each sample run in triplicate, and UV trans-illumination (1 min) images were obtained to control for loading (Bio-Rad ChemiDoc MP Imaging System, Spain). The proteins were then transferred to a PVDF membrane and after blocking for $30 \mathrm{~min}$ in $5 \% \mathrm{BSA}$, the membranes were probed overnight at $4{ }^{\circ} \mathrm{C}$ with a mouse anti- $\beta$-actin antibody (1:200,000 dilution: Sigma (A1978), Japan). The membranes were washed thrice with $0.01 \%$ Triton-X 100 in PBS and incubated for 1 hour with the secondary antibody (1:10,000 dilution: ThermoFisher 926-32210, Spain). After washing, images were obtained on an Odyssey CLx Infrared Imaging System (Li-Cor, USA) and the protein bands were quantified with ImageJ software (USA). The $\beta$-actin levels were normalized to the total protein level.

\subsection{Adhesion assay}

Cells ( $1 \times 10^{4}$ cells/coverslip) were plated on $13 \mathrm{~mm}$ round glass coverslips and incubated for 1 hour at 37 ${ }^{\circ} \mathrm{C}$ in $5 \% \mathrm{CO}_{2}$ prior to fixation, each sample was studied in triplicate. The cells were then washed with PBS and fixed for 20 min with 4\% PFA (Sigma, USA) in PBS. The nuclei were stained with DAPI (1:5,000 dilution, Panreac Applichem A4099, Spain) and all the coverslips were mounted with Fluoro-Gel medium (Electron Microscopy Sciences, USA). The images were acquired on an Olympus BX40 microscope equipped with an Olympus DP73 camera (Spain) at 20X and the total number of cells attached to the coverslips was quantified.

\subsection{Wound healing assay}

The assay was performed as indicated in the datasheet for the "Wound Healing Assay" (Ibidi, Germany). A $70 \mu \mathrm{l}$ suspension of a $3 \times 10^{5}$ cells was added into each well of the 2 Well Culture-Insert and after 24 hours, when the cell monolayer was confluent, the 2 Well Culture-Insert was removed and fresh medium was added. At this point (0 hours) a wound was made in the culture, which was free of cells, and images were then taken at 0,24 and 48 hours in order to quantify the number of cells migrating into the wound and the percentage closure. Each sample was studied in triplicate.

\subsection{Apoptosis assay}

Apoptosis was evaluated by flow cytometry by measuring the levels of Annexin V (A) and Propidium Iodide (PI). Briefly, cells $\left(2 \times 10^{4}\right.$ cells/well $)$ were seeded in 6 -well plates and incubated with Dulbecco's Modified Eagle Medium/Ham F-12 (DMEM/F12) containing 10\% Foetal Bovine Serum (FBS), 2\% GlutaMAX 100X and $1 \%$ antibiotic-antimycotic (Thermo Scientific, Spain) for $24 \mathrm{~h}$, at $37{ }^{\circ} \mathrm{C}, 5 \% \mathrm{CO}_{2}$. ON cells were detached with $0.25 \%$ trypsin-EDTA (GibcoBRL, USA), and incubated with anti-Annexin V (PB-V450, \#560506, BD) and PI (\#556463, BD) at $4^{\circ} \mathrm{C}, 30$ min. Fluorescence was measured with a Cytoflex cytometer (Beckman Coulter) and the CytoExpert software. Finally, data were analysed with FlowJo v 10.4 software.

\subsection{Statistical analysis}

For the demographic and clinical categorical data (gender and tobacco use), the differences between the controls and cannabis users were assessed with a two-tailed chi-squared test. Protein-related statistics were obtained with Progenesis LC-MS (Waters, USA) and the IPA software (QIAGEN, Germany) while functionalrelated statistical analysis was performed with GraphPad Prism 5 software (GraphPad Software, USA). For functional assays, the difference between the control and cannabis users was assessed using the Student's 
t-test (unpaired, two-tailed) after a normal distribution was evaluated with a Kolmogorov-Smirnov test. Correlations were performed using a Pearson's test to evaluate the association between every neuropsychological test score, and the THC-COOH and 11-OH-THC plasma levels. The data were presented as means \pm SEM and the differences were considered statistically significant at a $\mathrm{p}$ value $<0.05$.

\section{RESULTS}

\subsection{There are no differences in the demographic or clinical characteristics of cannabis users}

When the demographic and clinical data of all the subjects was assessed (Table 1), no significant differences were observed between the control subjects and the cannabis users in terms of age, sex, weight, height, body mass index, tobacco use or clinical assessment (premorbid intelligence quotient (IQ) and depressive symptoms).

\subsection{Cannabis consumption is related to worse attentional performance}

THC and its metabolites were measured in plasma and no THC was detected in the control subjects or the cannabis users. The metabolites of THC were not detected in the control subjects $(n=7)$, whereas among the cannabis users $(\mathrm{n}=6)$, plasma 11-OH-THC was found in 5 out of 6 subjects (mean concentration: $1.68 \pm 0.55 \mathrm{ng} / \mathrm{ml})$ and THC-COOH was detected in all of these subjects $(29.76 \pm 6.15 \mathrm{ng} / \mathrm{ml})$. The neuropsychological assessment (Fig. 1) revealed that cannabis users exhibited significantly worse attentional performance than healthy controls in the spatial span direct recall test $(\mathrm{p}<0.01$, Fig. 1A), consistent with previous data (Galindo et al., 2018). Furthermore, a trend towards worse working memory was also detected in the spatial span inverse recall test $(\mathrm{p}=0.068$, Fig. $1 \mathrm{D})$.

\subsection{Fewer undifferentiated ON cells were obtained from cannabis users}

Under proliferative conditions, the markers $\mathrm{CD}_{105}{ }^{+}, \mathrm{Nestin}^{+}, \mathrm{GFAP}^{+}, \beta$-III-Tubulin ${ }^{+}$and $\mathrm{GAP} 43^{+}$were detected in ON cells derived from control subjects $24 \mathrm{~h}$ post seeding (Fig. 2), reflecting the presence of mesenchymal cells (CD105), undifferentiated neural progenitors (Nestin), glial-like cells (GFAP) and immature neurons ( $\beta$-III-Tubulin and GAP43), as described previously (Feron et al., 2005; Delorme et al., 2010; Borgmann-Winter et al., 2015). A high proportion of cells $(60-80 \%)$ were Nestin ${ }^{+}$and/or $\beta$-IIITubulin $^{+}$, indicating their neural lineage (Fig. 2D-F, J-L) (Benitez-King et al., 2011), yet no cells were positive for the multipotent stem cell marker, Sox2 (data not shown). Among the ON cells from cannabis users there was a significant decrease in the number of cells expressing the CD105 and GFAP markers $(\mathrm{t}=$ 2.887, $\mathrm{p}=0.0203$ and $\mathrm{t}=3.584, \mathrm{p}=0.0071$ respectively, Fig. $2 \mathrm{C}, \mathrm{I}$ ), and an increase in the Nestin ${ }^{+}$cells $(\mathrm{t}=2.318, \mathrm{p}=0.0491$, Fig. $2 \mathrm{~F})$. No changes were observed in the percentage of $\beta$-III-Tubulin or GAP43 ${ }^{+}$ cells $(\mathrm{t}=0.1724, \mathrm{p}=0.8674$ and $\mathrm{t}=0.3198, \mathrm{p}=0.7573$ respectively, Fig. 2L, O).

\subsection{ON cells from cannabis users show proteomic alterations}

The label-free proteomic approach allowed the identification of 65 proteins that were differentially expressed between ON cells derived from control subjects and cannabis users (49 upregulated and 16 downregulated). By analysing the list of differentially expressed proteins with IPA, we obtained information about the alterations induced in canonical pathways, the molecular/cellular functions, the development of physiological systems, and related diseases and disorders (Figs. 3-4). Remarkably, differentially expressed proteins in cannabis users were related to several canonical pathways, including Integrin, Integrin-linked kinase (ILK), Focal Adhesion Kinase (FAK) and Actin Cytoskeleton signalling, as well as on cell behavior like Fc Receptormediated phagocytosis, microtubule dynamics and its influence on cell morphology, cell development, and at the level of tissue assembly and organization. In addition, the changes affected cell growth and proliferation, and inhibited cell death (Fig. 4B-C). These pathways and activities are of interest because they play an important role in nervous system development and function (Sacco et al., 2018). Indeed, 19 proteins involved in nervous system development and activity were differentially expressed in ON cells from cannabis users (Fig. 3B), alterations to which has also been described in mental disorders and brain (neurological) pathologies (Hakak et al., 2001; Bowden et al., 2008; Morin et al., 2009; Green et al., 2013; Volk and Lewis, 2016). Indeed, some of the differentially expressed proteins identified were related to disorders like schizophrenia, 
DiGeorge syndrome, epilepsy or bipolar disorder (Fig. 4D). Complete and detailed information regarding proteins changes can be found in the Supplementary Table 1.

Overall, according to IPA the proteins, altered in ON cells from cannabis consumers were apparently involved in pathways related to cell viability, morphology and more importantly, neuronal development and function.

\subsection{ON cells from cannabis users have a distinct morphology}

Taking into account the proteomic results, we evaluated the potential changes in cell morphology by measuring the area and perimeter occupied by microtubules stained with $\beta$-III-Tubulin, as well as the cell shape (Fig. 5). After measuring 100 cells in each sample, there was an increase in size of the cells obtained from cannabis users relative to the controls $(t=7.804, \mathrm{p}<0.0001$, Fig. 5B-D). Furthermore, a high percentage of cells had a roundness value between 2 and 4, with significant differences between groups in this parameter $(\mathrm{t}=2.804, \mathrm{p}=0.021$, Fig. $5 \mathrm{E})$. These changes in cell morphology might be explained by the alterations in the proteomic assay, with an up-regulation of proteins related to actin cytoskeleton signalling (Fig. 3A). Moreover, we observed an increase in the $\beta$-Actin in cells derived from cannabis users when measured in western blots $(t=3.254, p=0.031$, Fig. $5 F-G)$. Together, these data indicate that the cytoskeleton was altered in cells derived from cannabis users, with consequences for cell size and shape.

\subsection{Cannabis reduced adhesion while it did not modify migration}

In cell adhesion experiments, there were no initial differences in the number of dead cells, with $99.9 \%$ viability in both the experimental groups when assessed by trypan blue exclusion (data not shown). However, we did observe a decrease in the total number of attached ON cells derived from cannabis users, indicating a weaker adhesive capacity $(\mathrm{t}=2.730, \mathrm{p}=0.0293,3$ replicates/cell line, Fig. $5 \mathrm{H}-\mathrm{J})$. We also quantified the number of focal adhesions in monolayer cultures of cells immunolabelled with anti-vinculin (Fig. 5K-L) and there were fewer focal adhesions in cells derived from cannabis users $(t=3.859, \mathrm{p}=0.0048$, Fig. 5M). Whether the decrease in adhesion was related to an increase in cell migration was determined in a "scratch wound" assay, yet there were no differences in the migration rate of cells from control subjects and cannabis users (percentage closure: $\mathrm{t}=0.4176, \mathrm{p}=0.6872$; number of cells: $\mathrm{t}=0.4619, \mathrm{p}=0.6565$, Fig. $5 \mathrm{~N}-\mathrm{P}$ ). Nevertheless, the proteomic analysis identified differentially expression of several proteins related to cell migration.

\subsection{Cannabis affects cell proliferation and viability but not cell differentiation}

Cell proliferation was evaluated by immunostaining cells for the specific Ki67 marker (Fig. 6D-E) and there was an increase in the number of proliferative ON cells from cannabis users relative to the controls $(\mathrm{t}=$ $4.212, \mathrm{p}=0.0029$, Fig. $6 \mathrm{~B}$ ). This increase was consistent with the proteomic analysis in which there was an up-regulation of cell growth and proliferation proteins in cells from cannabis users (Fig. 4C) and proteins involved in cell cycle regulation (Supplementary Fig. 1). Despite the increase in proliferation, the total number of cells in culture was no different between the two groups $(t=0.393, p=0.704$, Fig. $6 \mathrm{C})$.

To evaluate whether the changes in cell proliferation may affect differentiation, the expression of the NeuN neuronal marker and the GFAP astrocyte marker was assessed (Fig. 6G-J). After 7 days in culture, 40.22\% of the cells were $\mathrm{NeuN}^{+}$in both groups, whereas no $\mathrm{GFAP}^{+}$cells were detected, indicating a high degree of mature cells expressing a neuronal, but not a glial marker. However, no differences were observed between groups in $\mathrm{NeuN}^{+}$labelling $(\mathrm{t}=0.0889 \mathrm{p}=0.9313$, Fig. $6 \mathrm{~F})$.

Finally, proteomic results indicated a potential down-regulation of cell death, based on the differential expression of the proteins identified (Fig. 4B). We observed a significant decrease in the proportion of Annexin V+/PI- and Annexin V+/PI+ cells derived from cannabis users relative to the controls, indicating a decrease in both early and late apoptosis in $\mathrm{ON}$ cells from cannabis users $(\mathrm{t}=2.975, \mathrm{p}=0.0177$ and $\mathrm{t}=$ $2.827, \mathrm{p}=0.0222$ respectively: Fig. $6 \mathrm{~K}-\mathrm{O})$, consistent with the proteomic data.

\section{DISCUSSION}

We show here that ON cells derived from cannabis users suffer cytoskeleton alterations, decreased attachment, enhanced cell proliferation and reduced cell death. These behavioural alterations are accompanied 
by changes in the expression of proteins that have been associated with cancer, gastrointestinal disease and neurodevelopmental pathways (Prescot et al., 2011; Jacobus and Tapert, 2014; Gubatan et al., 2016; Ghasemiesfe et al., 2019). Thus, the ON cell model provides relevant information regarding the effects of cannabis on the brain that may be related to neuropsychiatric disorders.

ON cells are morphologically undifferentiated after $24 \mathrm{~h}$ in vitro, and most of them (>90\%) express an antigen associated with bone marrow stromal cells (CD105), as indicated previously (Matigian et al., 2010). Furthermore, $60-80 \%$ express the markers of neural progenitors (Nestin) and/or immature neurons ( $\beta$-IIITubulin and GAP43) (Matigian et al., 2010; Galindo et al., 2018) corroborating their neural lineage. Moreover, around $20 \%$ of cells express GFAP, indicating the presence of astroglial-like cells previously described as neuroblasts in ON cell populations (Wolozin et al., 1992; Hahn et al., 2005). Furthermore, multipotent stem cell marker, Sox2, expressed by ON (Lin et al., 2017) was not detected in our cell cultures. ON cells from cannabis users also expressed the same markers as control cells, although there were significantly fewer $\mathrm{CD}_{105^{+}}$and $\mathrm{GFAP}^{+}$cells, and more Nestin ${ }^{+}$cells in these cultures. Nestin and GFAP are thought to be neural progenitor and stem cell markers, respectively (Wolozin et al., 1992; Benitez-King et al., 2011), indicating that these cells are in a different stage of cell growth. Thus, the change we observed in the number of $\mathrm{Nestin}^{+}$and $\mathrm{GFAP}^{+}$cells could be explained by alterations in cell growth and differentiation. Likewise, a decrease in CD105 is associated with the differentiation of mesenchymal stem cells derived from different tissues (Jin et al., 2009; Alev et al., 2010; Noda et al., 2019). By contrast, we did not observe a change in the number of immature $\beta$-III-Tubulin ${ }^{+}$and GAP4 $3^{+}$cells after $24 \mathrm{~h}$ in vitro, nor in the number of $\mathrm{NeuN}^{+}$ cells after 7 days in vitro, indicating that the changes in the number of neuronal progenitors present in the ON of cannabis users do not necessarily lead to ON cell differentiation.

We evaluated the proteomic profile of ON cells after 5 days in vitro, identifying 49 upregulated proteins and 16 downregulated proteins in the cells from cannabis users as compared to cells from healthy controls. Several proteins involved in the actin cytoskeleton signaling pathway, and in the Integrin and ILK signaling pathways, were significantly affected in ON cells from cannabis users. ILK fulfils an essential role in connecting the cytoplasmic tail of integrin $\beta$ subunits to the actin cytoskeleton and in regulating actin polymerization. These proteomic data were in agreement with changes in cell morphology that was assessed by measuring the size and shape of $\beta$-III-Tubulin stained cells. In control ON cells, microtubules form an extensive and compact network that appears to originate from the microtubule organizing centre located close to the nucleus. There was a robust increase in the size of $\beta$-III-Tubulin stained ON cells from cannabis users, with differences in roundness that suggests a reorganization of microtubules. Furthermore, changes in microtubule assembly were accompanied by stronger $\beta$-actin expression in ON cells from cannabis user that was evident in western blots, suggesting that two cytoskeletal structures may be significantly affected by cannabis, microtubules and microfilaments. The cytoskeleton is involved in a number of biological processes, ranging from those that involve the maintenance of cell shape to those affecting cell proliferation and other activities (Pedersen et al., 2001; Fletcher and Mullins, 2010; Kapitein and Hoogenraad, 2015). The mechanisms by which cannabis alters cytoskeletal architecture are unknown, although THC was shown to influence the assembly and disassembly of tubulin in vitro (Tahir and Zimmerman, 1991). Since the cytoskeleton is closely associated with cell membranes, the interaction of cannabis with the lipid bilayer or membrane bound enzyme systems may adversely affect the architecture of the cytoskeleton. In this sense, a recent study using SR-FTIR spectroscopy found that intracellular lipid chains are disordered in ON cells from cannabis users, the membrane displaying an altered lipid composition with a higher rate of membrane lipid renewal and peroxidation, and more proteins with $\beta$-sheet structures (Saladrigas-Manjon et al., 2020). Thus, these data strongly support the increased cell size and cytoskeletal alteration in the ON cells of cannabis users. Interestingly, earlier data showed that ON cells from bipolar patients were larger and displayed cytoskeletal alterations (Solis-Chagoyan et al., 2013).

Cannabis may also affect the cytoskeleton indirectly through its effects on other cell structures or biochemical activities. Indeed, cytoskeletal abnormalities may be related to other cell functions like cell adhesion and migration. ACTG1, DOCK1 and RAP1B also belong to FAK signalling and Paxillin pathways (Figure 3 and 4). Paxillin is a focal adhesion-associated phosphotyrosine-containing protein. The proteomic alterations to 
these pathways suggest there are changes at the cell surface of ON cells from cannabis users, as demonstrated by the weaker vinculin staining in $\mathrm{ON}$ cells from cannabis users and the decrease in the total number of attached cells when adhesion was evaluated. Interestingly, schizophrenic ON cells have half the size and number of focal adhesion (Fan et al., 2013; Munoz-Estrada et al., 2015; Tee et al., 2017), and as focal adhesions are related to cell attachment, detachment and migration (Tee et al., 2017), we evaluated the motility of these cells. While no changes in cell migration were detected, there were differences in the expression of proteins involved in migration (CD9, DOCK1, FERMT2, RAP1B, CAPZB, RAB35, ARPC2, SLC2A1, SYNE1, SYNE2, MGLL and CALD1). Many of these proteins are not exclusively involved in migration, which could explain why the alterations in their expression did not affect migration (e.g. DOCK1 or RAP1B are also involved in actin cytoskeletal signaling). Hence, the effects of cannabis use on ON cell migration should be studied further, for example assessing the migration of these cells in response to different extracellular matrix factors (Tee et al., 2017).

In terms of cell proliferation, ON cells from cannabis users had a higher rate of proliferation when evaluated with the Ki67 marker. However, cell differentiation was not affected, as the number of $\mathrm{NeuN}^{+}$neurons and $\mathrm{GFAP}^{+}$astrocytes did not change, even though the proteomic analysis suggested alterations in neural proliferation and axon guidance. In this sense, the STMN2 (stathmin-2) protein is particularly relevant as it is involved in axon guidance and the Endocannabinoid Developing Neuron pathway, and the downregulation seen for in STMN2 was consistent with the low levels detected in the human brains exposed to THC (Tortoriello et al., 2014). By reducing STMN2, THC favours ectopic filopodia formation and it alters axon morphology (Tortoriello et al., 2014). Furthermore, ON cells from cannabis users underwent less apoptosis, both early (Annexin V+/PI-) and late apoptosis (Annexin $\mathrm{V}+/ \mathrm{PI}+$ ). Indeed, several proteins related to cell death were differentially expressed in ON cells from cannabis users. If these alterations were to occur in the foetal or young brain, they would alter the timing and balance of neuronal birth, differentiation and death, consequently affecting the timing and success of synaptic connectivity. Such changes would produce fundamental differences in brain function, as reported in chronic cannabis users (Kim et al., 2019; Newman et al., 2019). In fact, chronic cannabis appeared to directly affect cognitive function, specifically decreasing attentional performance.

Interestingly, increased cell proliferation and reduced cell adhesion was evident in olfactory cultures from individuals with schizophrenia, although no alterations to apoptosis were detected (Feron et al., 1999; McCurdy et al., 2006). Thus, it is likely that cannabis might predispose or precipitate alterations leading to other psychiatric diseases. Accordingly, the proteomic analysis identified protein alterations common to cannabis and schizophrenic patients, such as those in EWSR1, RAB32 and STMN2 (Hakak et al., 2001; Bowden et al., 2008). Indeed, EWSR1 was altered in the same direction in post-mortem superior temporal gyrus tissue and in peripheral blood lymphocytes from individuals with schizophrenia (Bowden et al., 2008). Monoglyceride lipase (MGLL-1) metabolizes the endogenous cannabinoid 2-arachidonoylglycerol and ON cells from cannabis users express this protein this protein weaklier, while 2-arachidonylglycerol metabolism is enhanced in the prefrontal cortex of subjects with schizophrenia (Volk and Lewis, 2016). Overall, these data showing similarities in ON cells derived from cannabis users and schizophrenia patients, reinforcing the link of cannabis use and a higher risk of suffering psychoses (Nielsen et al., 2017).

In addition to schizophrenia, the proteomic analysis revealed a reduction in TBX1 (T-box containing transcription factor) expression in ON cells from cannabis users. Haplo-insufficiency of TBX1 is thought to contribute significantly to the cardiovascular, endocrine and neurogenic phenotypes of DiGeorge Syndrome (DGS, 22q11.2 deletion syndrome -22q11DS) and Velo-Cardio-Facial Syndrome (Lindsay et al., 2001; Jonas et al., 2014). Indeed, approximately 23-30\% of late adolescents and young adults with DGS develop psychotic symptoms. Moreover, the TBX1 gene has been involved in the pathogenesis of schizophrenia in some patients (Ping et al., 2016). In animal models, congenic TBX1 heterozygous mice display autism-related behavioural phenotypes (Hiramoto et al., 2011; Takahashi et al., 2016). Mutations and haplo-insufficiency of the $T B X 1$ gene are sufficient to cause reduced pre-pulse inhibition, a behavioural abnormality that is associated with a schizophrenic endophenotype (Paylor et al., 2006) 
ON cells from patients with bipolar disease and from cannabis users share some characteristics. Indeed, ON cells from bipolar patients are also larger and have an altered cytoskeleton (Solis-Chagoyan et al., 2013), similar to the changes found in ON cells from cannabis users. Moreover, our proteomic analysis detected a down-regulation of SYNE1 (nesprin-1), and polymorphisms of this gene have been associated with susceptibility to bipolar and unipolar mood disorders (Green et al., 2013). Apart from mental disorders, proteins differentially expressed in our samples are also related to other neurological disorders, such as epilepsy (Katona, 2015), Glut1 syndrome (Brockmann, 2009), Charcot-Marie-Tooth disease (Alazami et al., 2014), deafness (Morin et al., 2009), spinocerebellar ataxia (Gros-Louis et al., 2007), microcephaly/epilepsy/diabetes syndrome (Shalev et al., 2014) and episodic choreoathetosis/spasticity (Weber and Lerche, 2009).

In summary, our data show that ON cells derived from cannabis users exhibit changes in cell morphology, weaker adhesion, and alterations to their cell cycle, cell growth and proliferation, although we did not observe any effects on differentiation. These changes could be related to alterations in cytoskeletal proteins and signalling pathways. All these cellular processes are important for brain development, maintenance and function. Moreover, some of these alterations have been described in ON cells of schizophrenia and bipolar patients, providing a possible link between cannabis consumption and the risk of suffering a psychiatric disorder.

\section{REFERENCES}

Alazami AM, Alzahrani F, Bohlega S, \& Alkuraya FS (2014). SET binding factor 1 (SBF1) mutation causes Charcot-Marie-tooth disease type 4B3. Neurology 82: 1665-1666.

Alev C, McIntyre BA, Ota K, \& Sheng G (2010). Dynamic expression of Endoglin, a TGF-beta co-receptor, during pre-circulation vascular development in chick. Int J Dev Biol 54: 737-742.

Benitez-King G, Riquelme A, Ortiz-Lopez L, Berlanga C, Rodriguez-Verdugo MS, Romo F, et al. (2011). A non-invasive method to isolate the neuronal linage from the nasal epithelium from schizophrenic and bipolar diseases. J Neurosci Methods 201: 35-45.

Benitez-King G, Valdes-Tovar M, Trueta C, Galvan-Arrieta T, Argueta J, Alarcon S, et al. (2016). The microtubular cytoskeleton of olfactory neurons derived from patients with schizophrenia or with bipolar disorder: Implications for biomarker characterization, neuronal physiology and pharmacological screening. Mol Cell Neurosci 73:84-95.

Benton AL (1983) Multilingual aplasia examination( 2nd ed edn.

Bloomfield MAP, Hindocha C, Green SF, Wall MB, Lees R, Petrilli K, et al. (2019). The neuropsychopharmacology of cannabis: A review of human imaging studies. Pharmacol Ther 195: 132-161.

Borgmann-Winter K, Willard SL, Sinclair D, Mirza N, Turetsky B, Berretta S, et al. (2015). Translational potential of olfactory mucosa for the study of neuropsychiatric illness. Transl Psychiatry 5:e527.

Bowden NA, Scott RJ, \& Tooney PA (2008). Altered gene expression in the superior temporal gyrus in schizophrenia. BMC Genomics 9: 199.

Brockmann K (2009). The expanding phenotype of GLUT1-deficiency syndrome. Brain Dev 31: 545-552.

Buchanan JT, Grillner S, Cullheim S, \& Risling M (1989). Identification of excitatory interneurons contributing to generation of locomotion in lamprey: structure, pharmacology, and function. J Neurophysiol 62: 59-69.

Campeny E, Lopez-Pelayo H, Nutt D, Blithikioti C, Oliveras C, Nuno L, et al. (2020). The blind men and the elephant: Systematic review of systematic reviews of cannabis use related health harms. Eur Neuropsychopharmacol 33: 1-35.

DeCoster MA (2010). Microscopy and image analysis of individual and group cell shape changes during apoptosis Microscopy: Science, Technology, Applications and Education. 
Delorme B, Nivet E, Gaillard J, Haupl T, Ringe J, Deveze A, et al. (2010). The human nose harbors a niche of olfactory ectomesenchymal stem cells displaying neurogenic and osteogenic properties. Stem Cells Dev 19: 853-866.

Endicott J, Spitzer RL, Fleiss JL, \& Cohen J (1976). The global assessment scale. A procedure for measuring overall severity of psychiatric disturbance. Arch Gen Psychiatry 33: 766-771.

Fan Y, Abrahamsen G, Mills R, Calderon CC, Tee JY, Leyton L, et al. (2013). Focal adhesion dynamics are altered in schizophrenia. Biol Psychiatry 74: 418-426.

Feron F, Perry C, Hirning MH, McGrath J, \& Mackay-Sim A (1999). Altered adhesion, proliferation and death in neural cultures from adults with schizophrenia. Schizophr Res 40: 211-218.

Fletcher DA, \& Mullins RD (2010). Cell mechanics and the cytoskeleton. Nature 463: 485-492.

Galindo L, Moreno E, Lopez-Armenta F, Guinart D, Cuenca-Royo A, Izquierdo-Serra M, et al. (2018). Cannabis Users Show Enhanced Expression of CB1-5HT2A Receptor Heteromers in Olfactory Neuroepithelium Cells. Mol Neurobiol 55: 6347-6361.

Ghasemiesfe M, Barrow B, Leonard S, Keyhani S, \& Korenstein D (2019). Association Between Marijuana Use and Risk of Cancer: A Systematic Review and Meta-analysis. JAMA Netw Open 2: e1916318.

Green EK, Grozeva D, Forty L, Gordon-Smith K, Russell E, Farmer A, et al. (2013). Association at SYNE1 in both bipolar disorder and recurrent major depression. Mol Psychiatry 18: 614-617.

Gros-Louis F, Dupre N, Dion P, Fox MA, Laurent S, Verreault S, et al. (2007). Mutations in SYNE1 lead to a newly discovered form of autosomal recessive cerebellar ataxia. Nat Genet 39: 80-85.

Gubatan J, Staller K, Barshop K, \& Kuo B (2016). Cannabis Abuse Is Increasing and Associated with Increased Emergency Department Utilization in Gastroenterology Patients. Dig Dis Sci 61:1844-1852.

Hahn CG, Han LY, Rawson NE, Mirza N, Borgmann-Winter K, Lenox RH, et al. (2005). In vivo and in vitro neurogenesis in human olfactory epithelium. J Comp Neurol 483: 154-163.

Hakak Y, Walker JR, Li C, Wong WH, Davis KL, Buxbaum JD, et al.(2001). Genome-wide expression analysis reveals dysregulation of myelination-related genes in chronic schizophrenia. Proc Natl Acad Sci U S A 98: 4746-4751.

Hiramoto T, Kang G, Suzuki G, Satoh Y, Kucherlapati R, Watanabe Y, et al. (2011). Tbx1: identification of a 22q11.2 gene as a risk factor for autism spectrum disorder in a mouse model. Hum Mol Genet 20: 4775-4785.

Jacobus J, \& Tapert SF (2014). Effects of cannabis on the adolescent brain. Curr Pharm Des 20: 2186-2193.

Jin HJ, Park SK, Oh W, Yang YS, Kim SW, \& Choi SJ (2009). Down-regulation of CD105 is associated with multi-lineage differentiation in human umbilical cord blood-derived mesenchymal stem cells. Biochem Biophys Res Commun 381: 676-681.

Jonas RK, Montojo CA, \& Bearden CE (2014). The 22q11.2 deletion syndrome as a window into complex neuropsychiatric disorders over the lifespan. Biol Psychiatry 75: 351-360.

Kapitein LC, \& Hoogenraad CC (2015). Building the Neuronal Microtubule Cytoskeleton. Neuron 87: 492-506.

Katona I (2015). Cannabis and Endocannabinoid Signaling in Epilepsy. Handb Exp Pharmacol 231: 285-316.

Kim SH, Yang JW, Kim KH, Kim JU, \& Yook TH (2019). A Review on Studies of Marijuana for Alzheimer's Disease - Focusing on CBD, THC. J Pharmacopuncture 22: 225-230.

Leung CT, Coulombe PA, \& Reed RR (2007). Contribution of olfactory neural stem cells to tissue maintenance and regeneration. Nat Neurosci 10: 720-726. 
Lin B, Coleman JH, Peterson JN, Zunitch MJ, Jang W, Herrick DB, et al. (2017). Injury Induces Endogenous Reprogramming and Dedifferentiation of Neuronal Progenitors to Multipotency. Cell Stem Cell 21: 761-774 e765.

Lindsay EA, Vitelli F, Su H, Morishima M, Huynh T, Pramparo T, et al. (2001). Tbx1 haploinsufficieny in the DiGeorge syndrome region causes aortic arch defects in mice. Nature 410: 97-101.

Maccarrone M, Maldonado R, Casas M, Henze T, \& Centonze D (2017). Cannabinoids therapeutic use: what is our current understanding following the introduction of THC, THC:CBD oromucosal spray and others? Expert Rev Clin Pharmacol 10: 443-455.

Matigian N, Abrahamsen G, Sutharsan R, Cook AL, Vitale AM, Nouwens A, et al. (2010). Disease-specific, neurosphere-derived cells as models for brain disorders. Dis Model Mech 3: 785-798.

McCurdy RD, Feron F, Perry C, Chant DC, McLean D, Matigian N, et al. (2006). Cell cycle alterations in biopsied olfactory neuroepithelium in schizophrenia and bipolar I disorder using cell culture and gene expression analyses. Schizophr Res 82:163-173.

Morin M, Bryan KE, Mayo-Merino F, Goodyear R, Mencia A, Modamio-Hoybjor S, et al. (2009). In vivo and in vitro effects of two novel gamma-actin (ACTG1) mutations that cause DFNA20/26 hearing impairment. Hum Mol Genet 18: 3075-3089.

Munoz-Estrada J, Benitez-King G, Berlanga C, \& Meza I (2015). Altered subcellular distribution of the 75-kDa DISC1 isoform, cAMP accumulation, and decreased neuronal migration in schizophrenia and bipolar disorder: implications for neurodevelopment. CNS Neurosci Ther 21:446-453.

Newman SD, Cheng H, Schnakenberg Martin A, Dydak U, Dharmadhikari S, Hetrick W, et al. (2019). An Investigation of Neurochemical Changes in Chronic Cannabis Users. Front Hum Neurosci 13: 318.

Nielsen S, Sabioni P, Trigo JM, Ware MA, Betz-Stablein BD, Murnion B, et al. (2017). Opioid-Sparing Effect of Cannabinoids: A Systematic Review and Meta-Analysis. Neuropsychopharmacology 42: 1752-1765.

Noda S, Kawashima N, Yamamoto M, Hashimoto K, Nara K, Sekiya I, et al. (2019). Effect of cell culture density on dental pulp-derived mesenchymal stem cells with reference to osteogenic differentiation. Sci Rep 9: 5430 .

Paylor R, Glaser B, Mupo A, Ataliotis P, Spencer C, Sobotka A, et al. (2006). Tbx1 haploinsufficiency is linked to behavioral disorders in mice and humans: implications for 22q11 deletion syndrome. Proc Natl Acad Sci U S A 103: 7729-7734.

Pedersen SF, Hoffmann EK, \& Mills JW (2001). The cytoskeleton and cell volume regulation. Comp Biochem Physiol A Mol Integr Physiol 130: 385-399.

Ping LY, Chuang YA, Hsu SH, Tsai HY, \& Cheng MC (2016). Screening for Mutations in the TBX1 Gene on Chromosome 22q11.2 in Schizophrenia. Genes (Basel) 7.

Prescot AP, Locatelli AE, Renshaw PF, \& Yurgelun-Todd DA (2011). Neurochemical alterations in adolescent chronic marijuana smokers: a proton MRS study. Neuroimage 57: 69-75.

Sacco R, Cacci E, \& Novarino G (2018). Neural stem cells in neuropsychiatric disorders. Curr Opin Neurobiol 48: 131-138.

Saladrigas-Manjon S, Ducic T, Galindo L, Fernandez-Aviles C, Perez V, de la Torre R, et al. (2020). Effects of Cannabis Use on the Protein and Lipid Profile of Olfactory Neuroepithelium Cells from Schizophrenia Patients Studied by Synchrotron-Based FTIR Spectroscopy. Biomolecules 10.

Shalev SA, Tenenbaum-Rakover Y, Horovitz Y, Paz VP, Ye H, Carmody D, et al. (2014). Microcephaly, epilepsy, and neonatal diabetes due to compound heterozygous mutations in IER3IP1: insights into the natural history of a rare disorder. Pediatr Diabetes 15:252-256. 
Solis-Chagoyan H, Calixto E, Figueroa A, Montano LM, Berlanga C, Rodriguez-Verdugo MS, et al. (2013). Microtubule organization and L-type voltage-activated calcium current in olfactory neuronal cells obtained from patients with schizophrenia and bipolar disorder. Schizophr Res 143: 384-389.

Szutorisz H, \& Hurd YL (2016). Epigenetic Effects of Cannabis Exposure. Biol Psychiatry 79: 586-594.

Tahir SK, \& Zimmerman AM (1991). Influence of marihuana on cellular structures and biochemical activities. Pharmacol Biochem Behav 40: 617-623.

Takahashi T, Okabe S, Broin PO, Nishi A, Ye K, Beckert MV, et al.(2016). Structure and function of neonatal social communication in a genetic mouse model of autism. Mol Psychiatry 21: 1208-1214.

Tee JY, Sutharsan R, Fan Y, \& Mackay-Sim A (2017). Cell migration in schizophrenia: Patient-derived cells do not regulate motility in response to extracellular matrix. Mol Cell Neurosci 80:111-122.

Tortoriello G, Morris CV, Alpar A, Fuzik J, Shirran SL, Calvigioni D, et al. (2014). Miswiring the brain: Delta9-tetrahydrocannabinol disrupts cortical development by inducing an SCG10/stathmin-2 degradation pathway. EMBO J 33: 668-685.

Volk DW, \& Lewis DA (2016). The Role of Endocannabinoid Signaling in Cortical Inhibitory Neuron Dysfunction in Schizophrenia. Biol Psychiatry 79: 595-603.

Weber YG, \& Lerche H (2009). Genetics of paroxysmal dyskinesias. Curr Neurol Neurosci Rep 9: 206-211.

Wechsler D (1997) Wechsler Adult Intelligence Scale. Third Edition edn.

Wolozin B, Sunderland T, Zheng BB, Resau J, Dufy B, Barker J, et al. (1992). Continuous culture of neuronal cells from adult human olfactory epithelium. J Mol Neurosci 3: 137-146.

Zhang X (2016). Quantitative Analysis of THC and its Metabolites in Whole Blood Using LC-MS/MS for Toxicology and Forensic LaboratoriesWaters, the science of what's possible.

FIGURE 1 
A

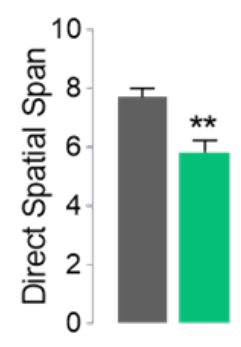

D

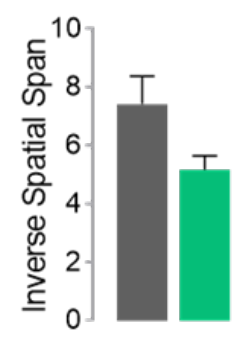

B

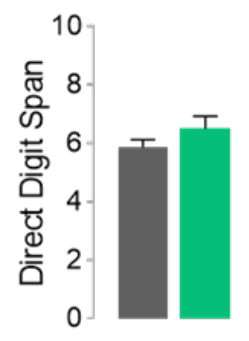

$\mathrm{E}$

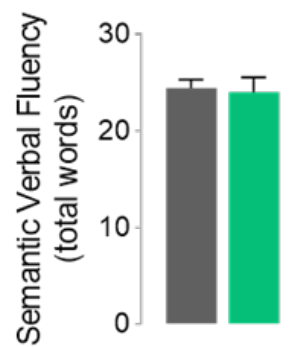

C

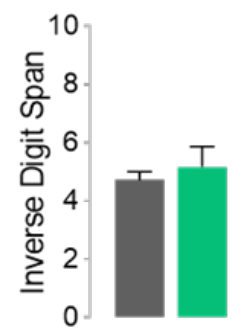

$\mathbf{F}$

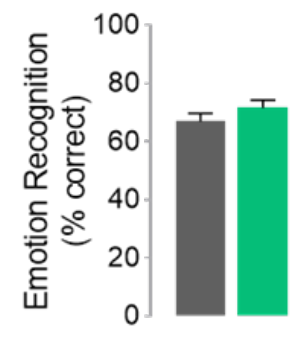

Figure 1. Neuropsychological assessment. A significant decrease in attention performance was observed in cannabis users when assessed by the direct spatial span test (A) but not the direct digit span test (B) . No significant differences between groups were observed in terms of working memory, assessed by the inverse digit span test (C) and the inverse spatial span test (D). Executive functions were evaluated with the verbal fluency test(E), and social and emotional cognition was assessed with the emotion recognition test $(\mathbf{F}):{ }^{*} \mathrm{p}<0,05$ (Student's t-test : Control subjects $\mathrm{n}=7$, Cannabis users $\mathrm{n}=6$ ).

\section{FIGURE 2}




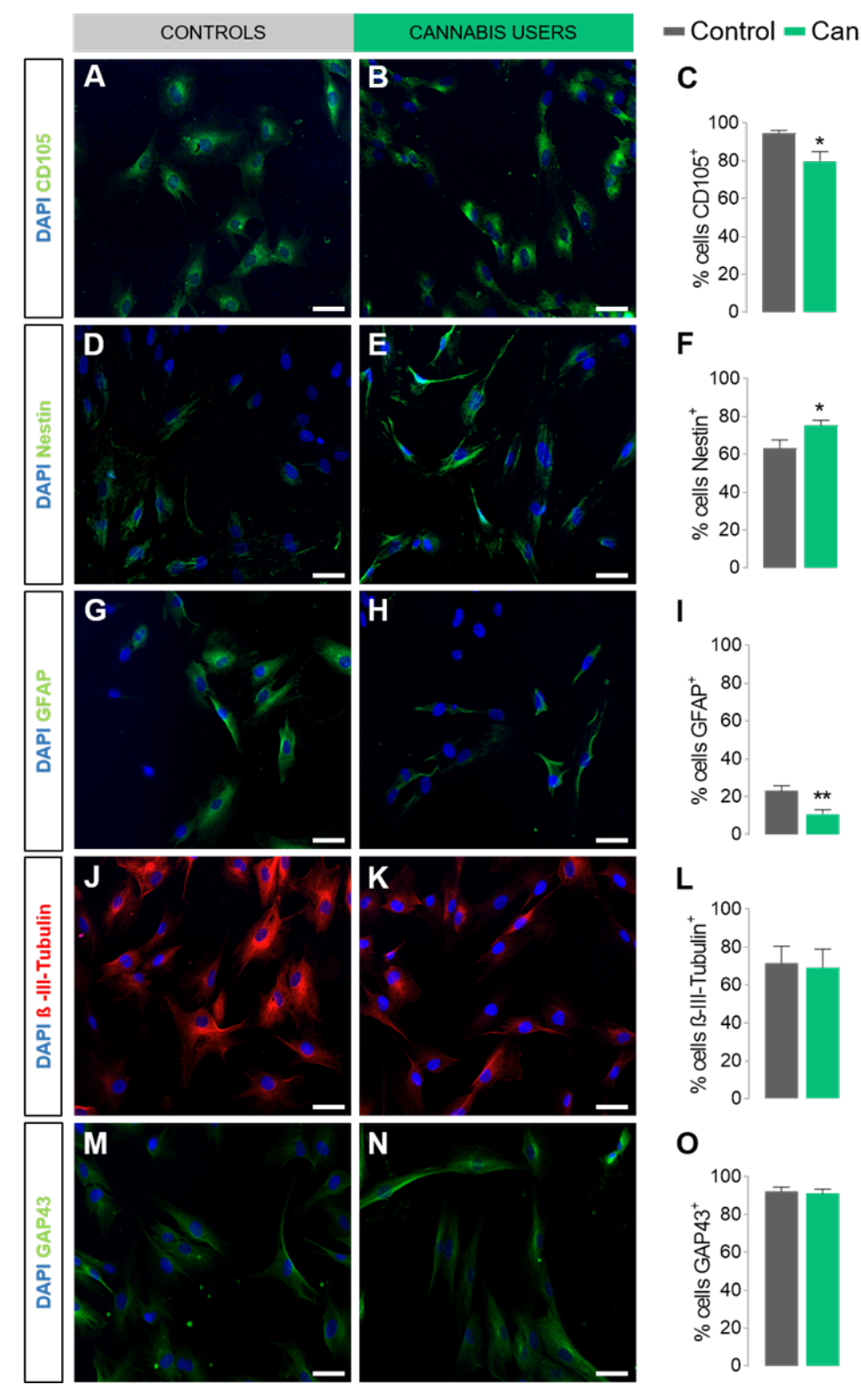

Figure 2. Cell types derived from the olfactory neuroepithelium (ON) of cannabis users and control subjects . Cells cultured to passage 6 were incubated for 24 hours under proliferative conditions. Representative immunofluorescence images and quantification of the different cell populations derived from a control subject and a cannabis user. Specific cell populations are immunolabelled in green or red and the nuclei are stained with DAPI. The quantification of the cells in each population is represented relative to the total cells $\left(\mathrm{DAPI}^{+}\right)$: (A-C) Mesenchymal CD105 ${ }^{+}$cells; (D-F) Nestin ${ }^{+}$neural progenitor cells; (G-I) Glial-like $\mathrm{GFAP}^{+}$cells. (J-L) Immature $\beta$-III-Tubulin neurons; (M-O) Immature GAP $43^{+}$neurons. Scale bar $=50 \mu \mathrm{m} .{ }^{*} \mathrm{p}<0.05 ;{ }^{* *} \mathrm{p}<0.001$ (Student's t-test , $\mathrm{n}=5$ ).

\section{FIGURE 3}


A. Top Canonical Pathways

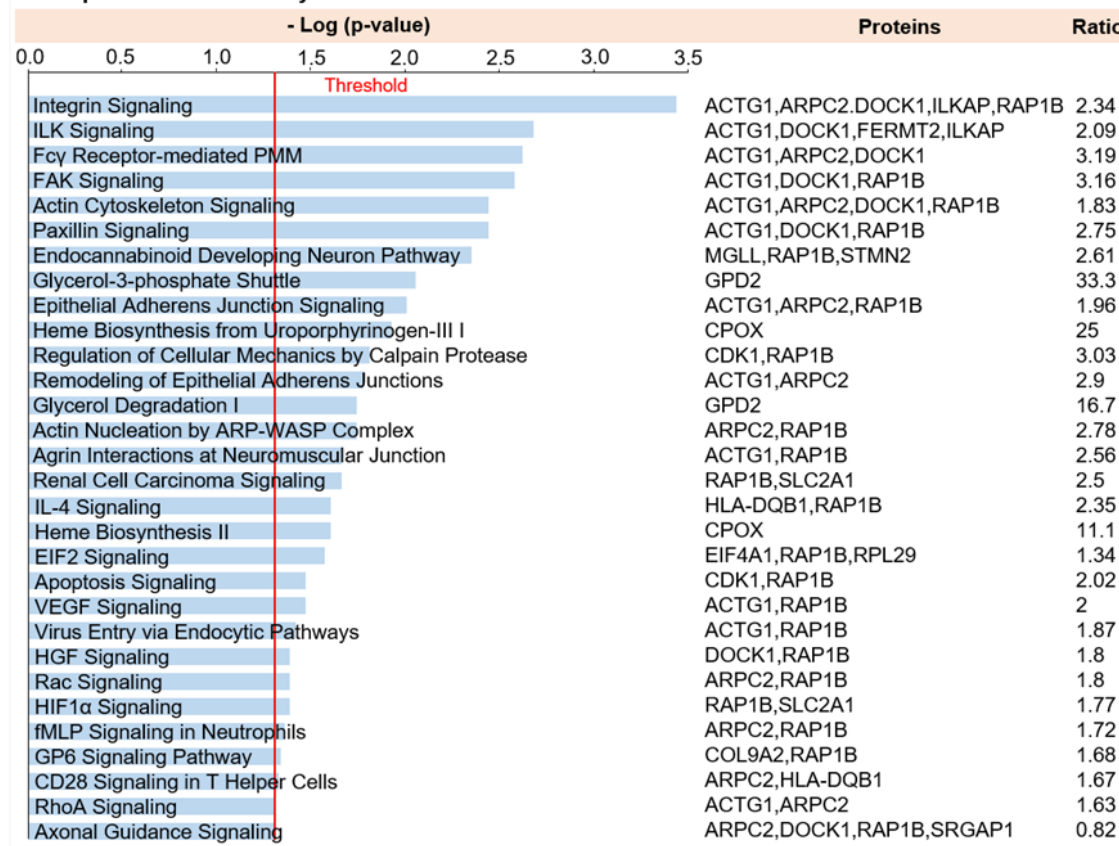

$\begin{array}{lcc}\text { B. Top Diseases and Bio Functions } & & \\ \text { 1. Molecular and Cellular Functions } & \text { p-value range } & \text { Proteins } \\ \text { Cellular Development } & 3.66 \mathrm{E}-02-1.69 \mathrm{E}-05 & 18 \\ \text { Cellular Growht and Proliferation } & 3.66 \mathrm{E}-02-1.69 \mathrm{E}-05 & 19 \\ \text { Cellular Function and Maintenance } & 3.93 \mathrm{E}-02-2.42 \mathrm{E}-05 & 25 \\ \text { Cellular Assembly and Organization } & 3.93 \mathrm{E}-02-2.87 \mathrm{E}-05 & 25 \\ \text { Cell Morphology } & 3.93 \mathrm{E}-02-5.23 \mathrm{E}-04 & 18 \\ & & \text { Proteins } \\ \text { 2. Physiological System Development and Function } & \text { p-value range } & 19 \\ \text { Nervous System Development and Function } & 3.66 \mathrm{E}-02-1.69 \mathrm{E}-05 & 21 \\ \text { Tissue Development } & 3.93 \mathrm{E}-02-1.69 \mathrm{E}-05 & 17 \\ \text { Organ Morphology } & 3.93 \mathrm{E}-02-1.81 \mathrm{E}-03 & 12 \\ \text { Reproductive System Development and Function } & 3.38 \mathrm{E}-02-1.81 \mathrm{E}-03 & 3 \\ \text { Cell-mediated Immune Response } & 3.66 \mathrm{E}-02-1.96 \mathrm{E}-03 & \\ & & \text { P-value range } \\ \text { 3. Diseases and disorders } & 3.93 \mathrm{E}-02-5.41 \mathrm{E}-06 & 64 \\ \text { Cancer } & 3.93 \mathrm{E}-02-5.41 \mathrm{E}-06 & 64 \\ \text { Organismal Injury and Abnormalities } & 3.93 \mathrm{E}-02-2.18 \mathrm{E}-05 & 60 \\ \text { Gastrointestinal Disease } & 3.93 \mathrm{E}-02-6.82 \mathrm{E}-04 & 13 \\ \text { Developmental Disorder } & 2.98 \mathrm{E}-02-6.82 \mathrm{E}-04 & 17 \\ \text { Hereditary Disorder } & & \end{array}$

Figure 3. Functional classification of the proteins differentially expressed in the olfactory neuroepithelium (ON) cells from cannabis users. Differentially expressed proteins were analyzed with the Ingenuity Pathways Analysis (IPA) software. (A)Proteins differentially expressed are involved in 30 canonical pathways, sorted by the p-values assigned by IPA. These pathways have p-values above the red line threshold and thus, they are predicted to be affected. The ratio indicates the number of differentially expressed proteins found relative to the total number of proteins involved in the pathway. (B) The proteins differentially expressed that are involved in the diseases and functions are indicated. The p-value range and number of proteins involved in each disease or activity are included.

\section{FIGURE 4}




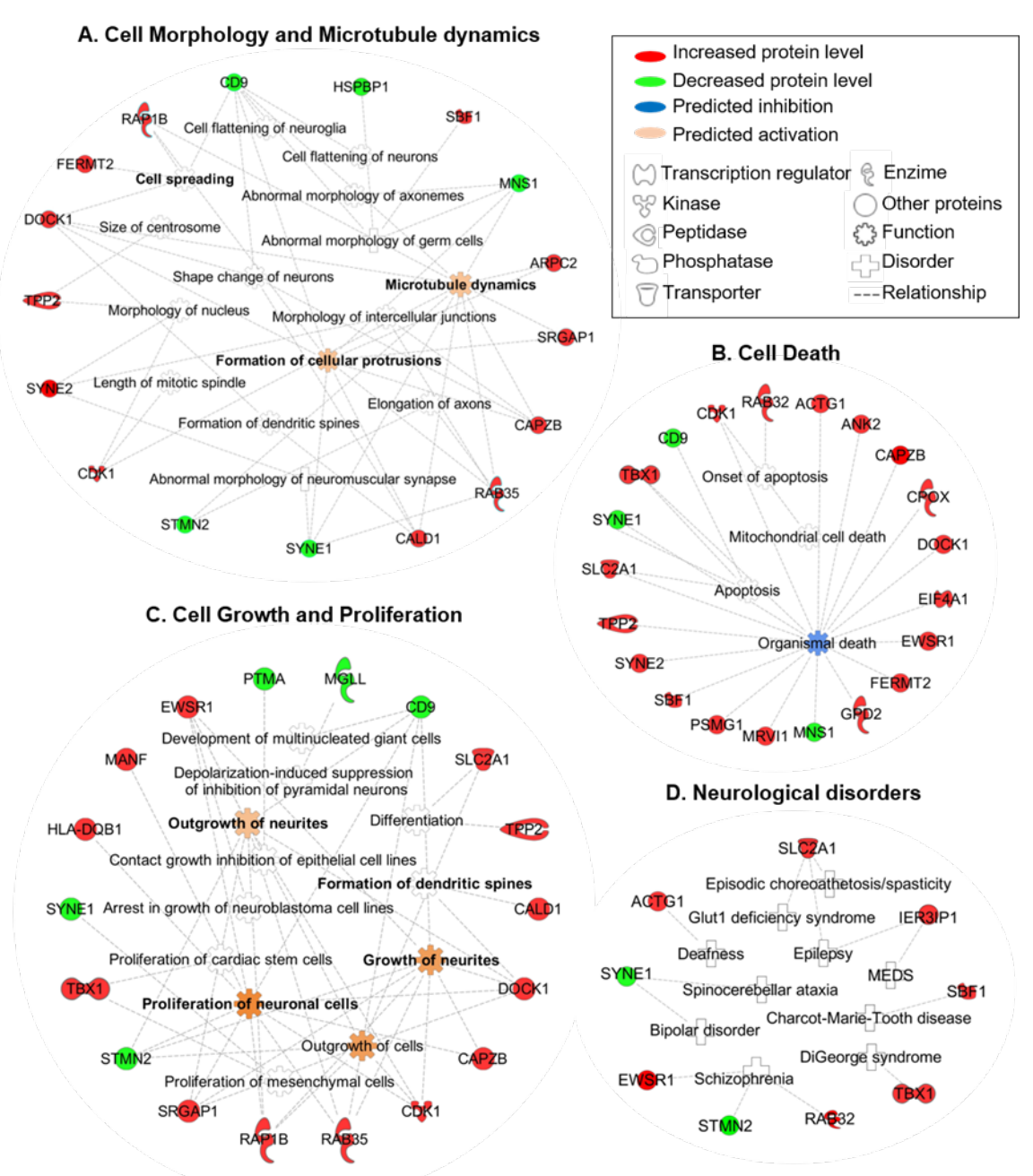

Figure 4. Graphical correlations between differentially expressed proteins in olfactory neuroepithelium $(\mathrm{ON})$ cells from cannabis users and their main related functions or diseases . The pathways were obtained from the Ingenuity Pathways Analysis (IPA) software. The proteins differentially expressed in the ON cells from cannabis users $(\mathrm{p}<0.05)$ are involved in: (A) cell morphology and microtubules dynamics, (B ) cell death, (C) cell growth and proliferation, and (D) hereditary and/or developmental neurological disorders. Proteins with enhanced expression are indicated in red and the more weakly expressed proteins are indicated in green. Based on the literature and databases, the functions that are predicted to be activated or inhibited are labelled in orange or blue, respectively. The type of proteins, functions or diseases are indicated by different shape icons. MED: Microcephaly, epilepsy and diabetes syndrome.

\section{FIGURE 5}



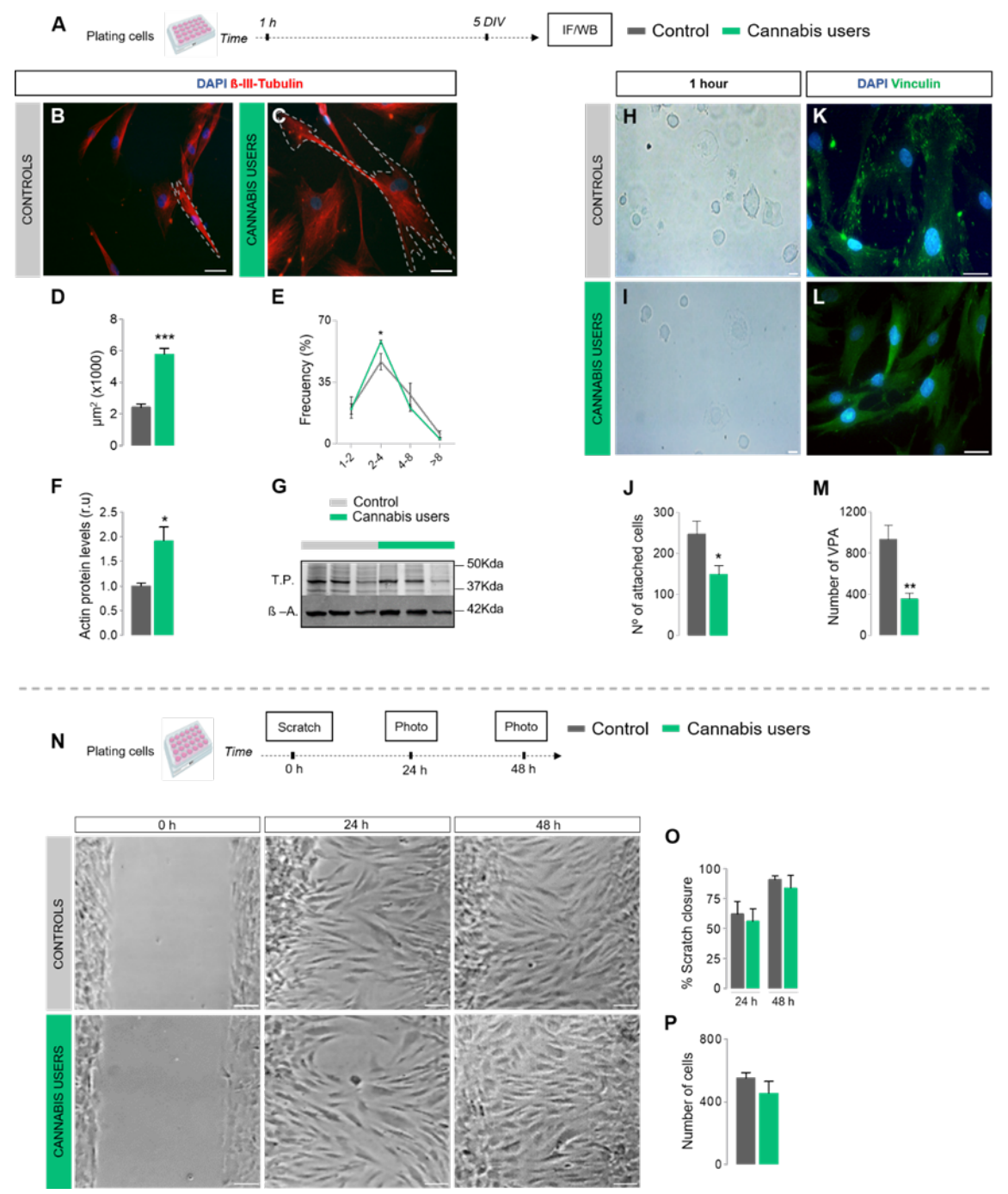

Figure 5. Analysis of the olfactory neuroepithelium (ON) cell's cytoskeletal morphology, adhesion and migration. (A) Cells were incubated for 1 hour or 5 days under proliferative conditions, after which they were analysed by immunofluorescences (IF) or in western blots (WB). (B, C) Representative immunofluorescence images of cultured cells derived from a control subject and a cannabis user, stained with anti- $\beta$-III-Tubulin (red) and DAPI (blue). The area and perimeter of cells were quantified by defining the stained area with ImageJ (dotted lines) (D) Quantification of cell area.(E) Quantification of the percentage of cells with specific roundness value intervals. (F, G ) Quantification of $\beta$-actin ( $\beta$-A) by western blots (r.u. $=$ relative units) normalized to the total protein content $(\mathrm{TP})$. (H, I) Representative bright field images of cells 1 hour after plating. (J) Quantification of the number of attached cells 1 hour after plating. (K, L ) Representative immunofluorescence images of cells in culture derived from a control subject and a cannabis user, stained for vinculin (green) and with DAPI (blue). (M) The number of vinculin points of adhesion (VPA) were quantified. (N) Representative bright field images at 0, 24 and 48 hours after scratching the cell monolayer. (O)Quantification of the percentage of closure in the wound area at 24 and 48 hours, relative to the baseline (t: $0 \mathrm{~h})$. (P) Quantification of the number of cells that migrated into the scratched area 24 $\mathrm{h}$ after scratching. Scale bar $=50 \mu \mathrm{m} .{ }^{*} \mathrm{p}<0.05 ;{ }^{* *} \mathrm{p}<0.001 ;{ }^{* * *} \mathrm{p}<0.001$ (Student's t-test, $\mathrm{n}=5$ ).

\section{FIGURE 6}



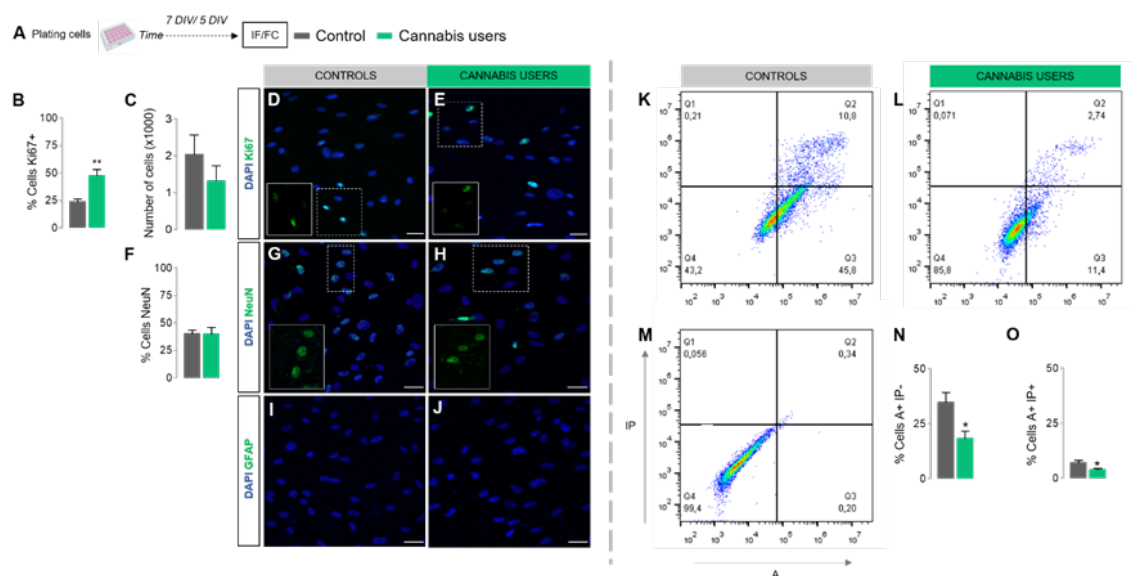

Figure 6. Analysis of the olfactory neuroepithelium (ON) cell's proliferation, differentiation and apoptosis. (A) Cells were incubated for 5 days under proliferative conditions, after which they were analysed by immunofluorescences (IF) or by flow cytometry (FC).(B) Quantification of proliferative Ki67 ${ }^{+}$cells relative to the total number of cells $\left(\mathrm{DAPI}^{+}\right)$.(C) Quantification of the total number of cells $\left(\mathrm{DAPI}^{+}\right)$in the culture. (D, E) Representative immunofluorescence images of cells in culture derived from control subjects and cannabis users. Cells under proliferation are immunolabelled in green $\left(\mathrm{Ki} 67^{+}\right)$ and nuclei are stained in blue (DAPI). Selected areas marked with dotted lines are showed in the white squares with the green labelling alone. (F)Quantification of differentiated $\mathrm{NeuN}^{+}$cells relative to the total number of cells $\left(\mathrm{DAPI}^{+}\right)$. (G-J)Representative immunofluorescence images of cells in culture derived from control subjects and cannabis users. Differentiated $\mathrm{NeuN}^{+}$and $\mathrm{GFAP}^{+}$cells are immunolabelled in green and nuclei are stained with DAPI (blue). Selected areas marked with dotted lines are showed in the white squares with the green labelling alone. (K-L) Representative flow cytometry plots of cells in culture derived from control subjects and cannabis users. (M) ON cells were labelled with Annexin V (A) and Propidium Iodide (PI) followed by flow cytometric analysis to measure apoptosis. The percentage of the following cell populations is indicated: A-/PI- are viable cells (lower left quadrant); A+/PI- are early apoptotic cells (lower right quadrant); and $\mathrm{A}+/ \mathrm{PI}+$ are late apoptotic cells (upper right quadrant). (N) Quantification of the percentage of cells in early (A+/PI-) and (O) late (A+/PI+) apoptosis. Scale bar $=50 \mu \mathrm{m} .{ }^{*} \mathrm{p}<0.05 ;{ }^{* *}$ $\mathrm{p}<0.001 ;$ (Student's t-test, $\mathrm{n}=5$ ).

\section{Hosted file}

070720 Tabla 1.docx available at https://authorea.com/users/353169/articles/477218-olfactoryneuroepithelium-cells-from-cannabis-users-display-alterations-to-the-cytoskeleton-andto-markers-of-adhesion-proliferation-and-apoptosis 